\title{
In situ erosion measurement tools for electric propulsion thrusters: triangular laser head and telemicroscope
}

\author{
Carsten Bundesmann ${ }^{1 *}$ (D), Christoph Eichhorn ${ }^{1}$, Horst Neumann ${ }^{1}$, Frank Scholze', Daniel Spemann ${ }^{1}$, \\ Michael Tartz ${ }^{1}$, Hans J. Leiter ${ }^{2}$, Roman Y. Gnizdor ${ }^{3}$ and Fabrizio Scortecci ${ }^{4}$
}

\author{
"Correspondence: \\ carsten.bundesmann@iom-leipzig.de \\ ${ }^{1}$ Tools Unit, Leibniz Institute of \\ Surface Engineering (IOM), Leipzig, \\ Germany \\ Full list of author information is \\ available at the end of the article
}

\begin{abstract}
The lifetime of electric propulsion (EP) thrusters depends particularly on the erosion characteristics of operation relevant components, for instance, the grid hole erosion of gridded ion thrusters or the channel wall erosion of Hall effect thrusters. Here two tools for in situ erosion measurements are presented, a triangular laser head for surface profiling and a telemicroscope for high-resolution optical imaging. Both can give access to radial and axial erosion parameters. The measurements can be done in situ without the need for breaking the vacuum and dismounting the thruster, which reduces thruster testing time considerably. In situ measurements can also help to ensure reproducibility of thruster performance conditions and can improve statistics of thruster characterization. The present work describes the fundamentals of both techniques in detail, selected experimental setups are presented, their performance is characterized and critically evaluated. The capabilities and limitations related to erosion measurements of EP thrusters are, exemplary, demonstrated for a gridded ion thruster RIT-22 and a Hall effect thruster SPT-100D.
\end{abstract}

Keywords: Electric propulsion; Gridded ion thruster; Hall effect thruster; Erosion measurements; Telemicroscope; Triangular laser head

\section{Introduction}

Electric propulsion (EP) thrusters have to undergo extensive testing before flying into space. Predominantly, ion beam and plasma parameters are of interest, because they determine the primary function of the thruster: producing thrust by acceleration of charged particles.

However, secondary parameters are also of interest. For instance, the erosion of operation relevant components must be measured and minimized in order to maximize thruster lifetime. Examples are the grid hole erosion of gridded ion thrusters or the channel wall erosion of Hall effect thrusters.

Erosion measurements can be done by profilometry using mechanical or optical (laserbased) profilers, or imaging techniques, such as white-light interferometry or optical microscopy using high-resolution tabletop microscopes or telemicroscopes.

(c) The Author(s) 2022. This article is licensed under a Creative Commons Attribution 4.0 International License, which permits use, sharing, adaptation, distribution and reproduction in any medium or format, as long as you give appropriate credit to the original author(s) and the source, provide a link to the Creative Commons licence, and indicate if changes were made. The images or other third party material in this article are included in the article's Creative Commons licence, unless indicated otherwise in a credit line to the material. If material is not included in the article's Creative Commons licence and your intended use is not permitted by statutory regulation or exceeds the permitted use, you will need to obtain permission directly from the copyright holder. To view a copy of this licence, visit http://creativecommons.org/licenses/by/4.0/. 
Typically, erosion measurements are done outside of the vacuum chamber. Here the thruster needs to be removed from the test stand and to be taken apart. If it was possible to do the measurements in situ, i.e. inside the vacuum chamber without breaking the vacuum, venting and evacuating of the vacuum chamber can be avoided. This can save several days per thruster characterization step and, hence, reduces costs. Furthermore, if the thruster does not need to be removed or taking apart, reproducibility of the thruster performance conditions is ensured. Finally, in situ measurements allow to increase the number of experiments, which gives a statistically more reliable thruster performance characterization.

In situ erosion measurements of different $\mathrm{EP}$ thrusters were reported using a triangular laser head (TLH, [1, 2]) or telemicroscopes [1-4]. Yuan et al. reported on the use of a telemicroscope for measuring in situ the grid deformation of a gridded ion thruster by videometrics [5].

Measurements of coordinates of the erosion profile points using a microscope provide not only quantitative data about erosion profile as a whole. The use of microscope also allows investigating microstructure of the erosion profile surface [6].

Recently, we were reporting on the advanced electric propulsion diagnostic (AEPD) platform [1, 2, 7], which consists of a modular, high-precision, five-axis positioning system and several diagnostic tools for ion beam and plasma characterization (Faraday probe, retarding potential analyzer, ExB probe, and active thermal probe), optical inspection (TLH, telemicroscope), and thermal characterization (pyrometer, thermocamera). All measurements can be done in situ, if needed all of them with a firing thruster.

Here, the fundamentals of TLH and telemicroscope measurements are described in detail. Selected experimental setups are presented, their performance is characterized and critically evaluated. The capabilities of the diagnostic tools are demonstrated, exemplary, for two EP thrusters: a gridded ion thruster RIT-22 [8, 9] and a Hall effect thruster SPT100D [10].

\section{Methods/experimental}

\subsection{Triangular laser head}

The TLH is a distance measurement tool. By scanning across an object, a surface profile can be obtained. The TLH utilizes a laser beam which hits the object (see Fig. 1). In general, the surface is rough such that the laser light is scattered in all directions. A portion of the scattered light with a certain emission angle range $\alpha \pm \Delta \alpha$ enters the detection side of the TLH and is focused by a lens on a position-sensitive detector. If the distance to the object is changed, scattered light with a different detection angle $\alpha$ enters the TLH and the position of the image spot on the detector changes.

Choosing a TLH, the following performance parameters need to be considered:

$\circ$ measurement range,

- spot size,

- accuracy,

- sampling rate,

o compactness,

- electrical connection/feedthrough,

- vacuum compatibility. 


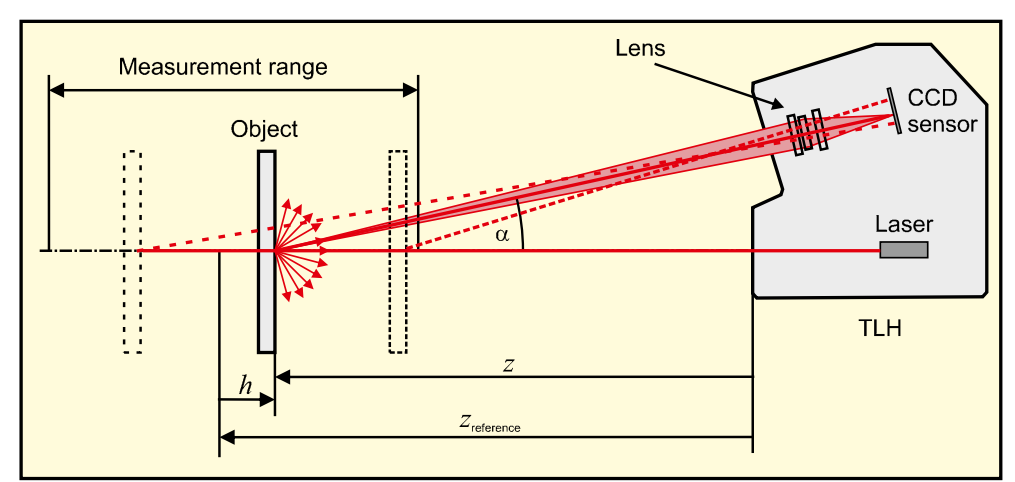

Figure 1 Schematic drawing of the working principle of a triangular laser head (TLH)

Table 1 Performance parameters of selected triangular laser heads (Source: https://www.keyence.co.uk/products/measure/laser-1d/lk-g3000/models/)

\begin{tabular}{llllllll}
\hline $\begin{array}{l}\text { Reference } \\
\text { distance } \\
{[\mathrm{mm}]}\end{array}$ & $\begin{array}{l}\text { Measurement } \\
\text { range }^{(a)}[\mathrm{mm}]\end{array}$ & $\begin{array}{l}\text { Minimum } \\
\text { spot size } \\
{[\mathrm{mm}]}\end{array}$ & $\begin{array}{l}\text { Linearity } \\
{[\mathrm{mm}]}\end{array}$ & $\begin{array}{l}\text { Repeatability } \\
{[\mu \mathrm{m}]}\end{array}$ & $\begin{array}{l}\text { Sampling } \\
\text { frequency } \\
{[\mu \mathrm{s}]}\end{array}$ & $\begin{array}{l}\text { Dimension } \\
{\left[\mathrm{mm}^{3}\right]}\end{array}$ & $\begin{array}{l}\text { Weight } \\
{[\mathrm{g}]}\end{array}$ \\
\hline 10 & \pm 1 & 0.02 & \pm 0.0003 & 0.02 & $20-1000$ & $54 \times 73 \times 27$ & 90 \\
30 & \pm 5 & 0.03 & \pm 0.0025 & 0.05 & $20-1000$ & $85 \times 77 \times 26$ & 280 \\
80 & \pm 15 & 0.07 & \pm 0.0075 & 0.2 & $20-1000$ & $95 \times 76 \times 36$ & 380 \\
150 & \pm 40 & 0.12 & \pm 0.02 & 0.5 & $20-1000$ & $83 \times 77 \times 34$ & 290 \\
400 & \pm 100 & 0.29 & \pm 0.05 & 2 & $20-1000$ & $108 \times 86 \times 37380$ \\
500 & -250 to +500 & 0.30 & \pm 0.1 to \pm 0.5 & 2 & $20-1000$ & $108 \times 86 \times 37380$ \\
\hline
\end{tabular}

(a) Given with respect to reference distance.

(b) Given at reference distance.

(c) Including cable.

Table 1 summarizes performance parameters of selected TLHs. There are many more commercially available, but the numbers given in the table seem to be representative. According to the numbers in Table 1, choosing the right TLH is always a compromise. For instance, choosing a large measurement range, results in an increase of the spot size and of the repeatability. As a consequence, radial and axial resolution are reduced.

The size of the TLH should be chosen as small as possible in order to minimize the interaction with the ion beam if measurements with a firing thruster need to be done. In this case, the TLH and especially the exit and entrance windows for the incident and scattered laser light should be shielded against direct ion impingement (see below).

The electrical connection needs an appropriate vacuum feedthrough. It is desirable to have a standard connection, where a vacuum feedthrough is commercially available. If this is not the case, a customized vacuum feedthrough with standard multi-pin connectors must be designed.

Please note, none of the manufacturers specify vacuum compatibility of their TLH. So check first, if the TLH has vacuum sensitive electronic or mechanical parts. If yes, replace or remove them. In general, the limiting factor seems to be the allowed maximum temperature, which is typically specified to be $50^{\circ} \mathrm{C}$. However, long term tests showed that vacuum compatibility is possible, even if the specified maximum temperature is temporarily exceeded. Still, the operation inside or close to the ion beam of the thruster needs to be minimized in order to avoid extensive external heating of the TLH. 

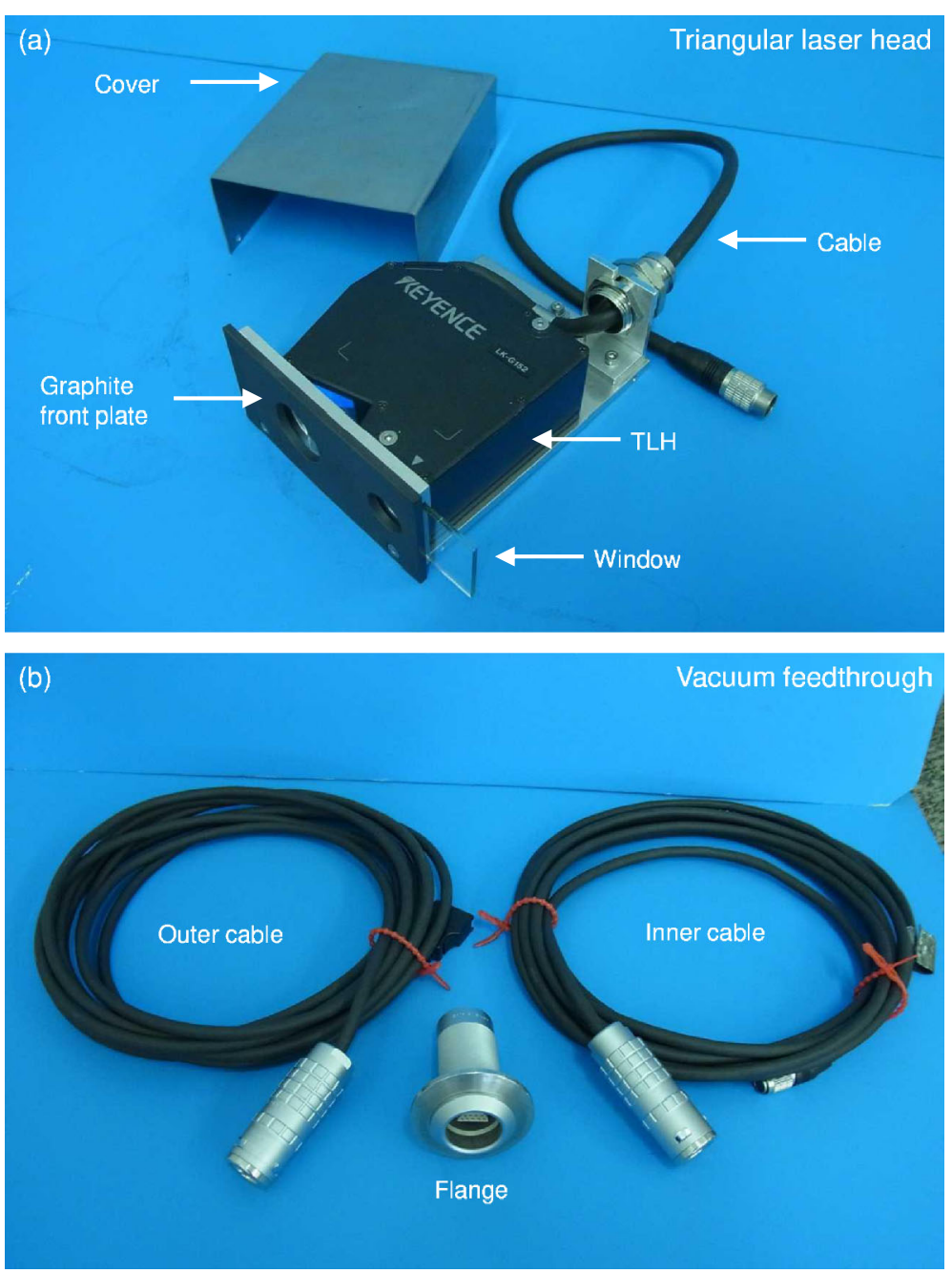

Figure 2 Experimental setup for in situ triangular laser head measurements: TLH with housing (a) and vacuum feedthrough with cables (b)

In the following experiments, a TLH L-KG152 (Keyence) was chosen. It provides a sufficient measurement range from $z=110 \mathrm{~mm}$ up to $z=190 \mathrm{~mm}$ (reference distance: $z_{\text {ref }}=150 \mathrm{~mm}$ ) with a small spot size between $0.12 \mathrm{~mm}$ at the reference distance and $0.75 \mathrm{~mm}$ at the far and near end of the measurement range, and a repeatability of 0.5 $\mu \mathrm{m}$.

For thruster test campaigns, the TLH is covered by a metal housing (see Fig. 2). The front side is shielded with a graphite plate, and glass or sapphire windows. The dimension of the housing is $95 \mathrm{~mm} \times 47 \mathrm{~mm} \times 127 \mathrm{~mm}$. The TLH uses special connectors. Therefore, a customized vacuum feedthrough with multi-pin connectors (Lemo) was designed and built.

Please note, since the detected, scattered light enters the shielding window at nonnormal incidence, it gets refracted and the direction of the transmitted light is displaced relative to the initial propagation direction (see Fig. 3). As a consequence, the measured distance is smaller than the geometrical distance. 


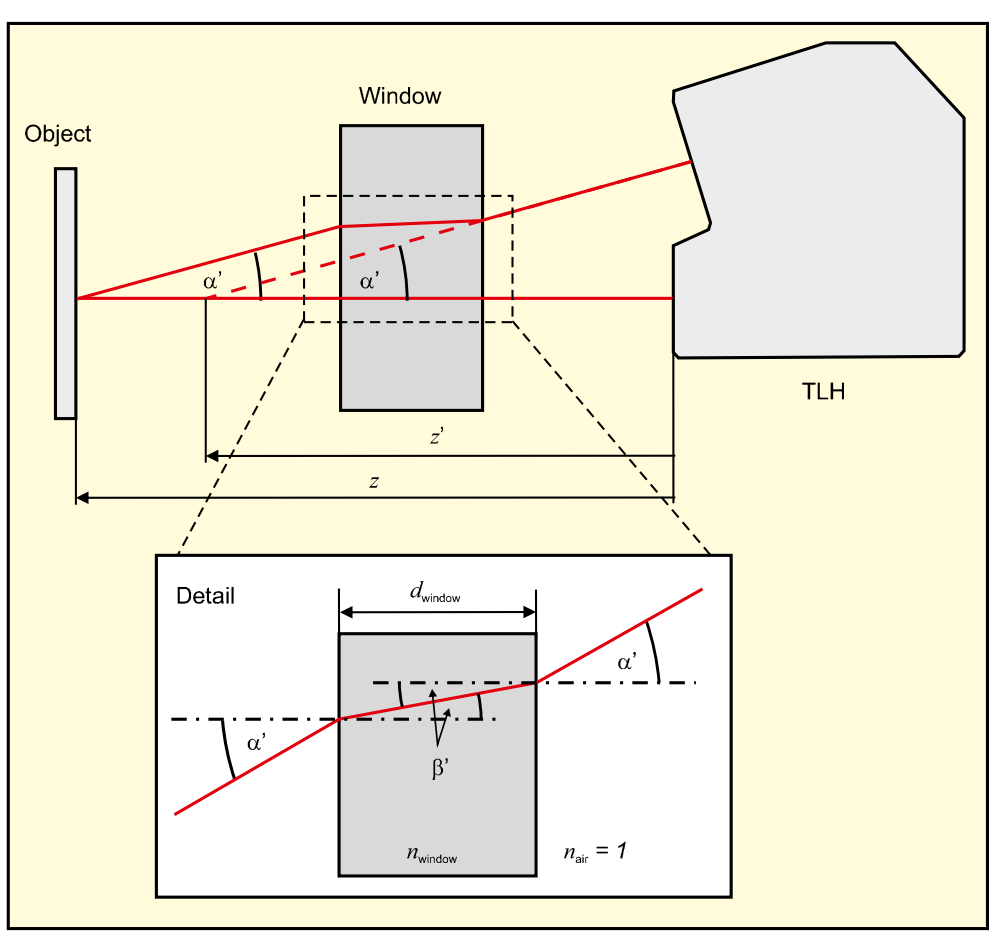

Figure 3 Illustration of the impact of a window on TLH measurement results (window effect): Due to refraction, the object appears to be closer than it is

The window effect can be calculated using Snell's law

$$
\frac{\sin \left(\alpha^{\prime}\right)}{\sin \left(\beta^{\prime}\right)}=n_{\text {window }}
$$

$\alpha^{\prime}$ and $\beta^{\prime}$ are the detection angle and angle of the refracted beam inside the window (see Fig. 3). The distance shift according to the window effect is given by

$$
\Delta z=z^{\prime}-z=\frac{\tan \left(\alpha^{\prime}\right)-\tan \left(\beta^{\prime}\right)}{\tan \left(\alpha^{\prime}\right)} \cdot d_{\text {window }}
$$

$n_{\text {window }}$ and $d_{\text {window }}$ are the index of refraction and thickness of the window, respectively.

Figure 4 summarizes experimental data of the preliminary characterization of the TLH without and with a window. The data were collected using a manual linear table with high precision (step width $0.01 \mathrm{~mm}$ ) and a maximum traveling range of $150 \mathrm{~mm}$. Prior to the measurements, the test object was aligned such that its surface is perpendicular to the laser beam propagation direction.

Figure 4(a) shows the difference between the set distance and the measured distance. Numbers are given relative to the reference distance of the TLH. It can be concluded that the distance measurement accuracy is better than $\pm 0.03 \mathrm{~mm}$ for flat surfaces. Please note, if absolute numbers of different measurement campaigns shall be compared, a fixed reference point must be defined. However, in most cases only relative numbers with respect to a point or plane on the test object are required. 

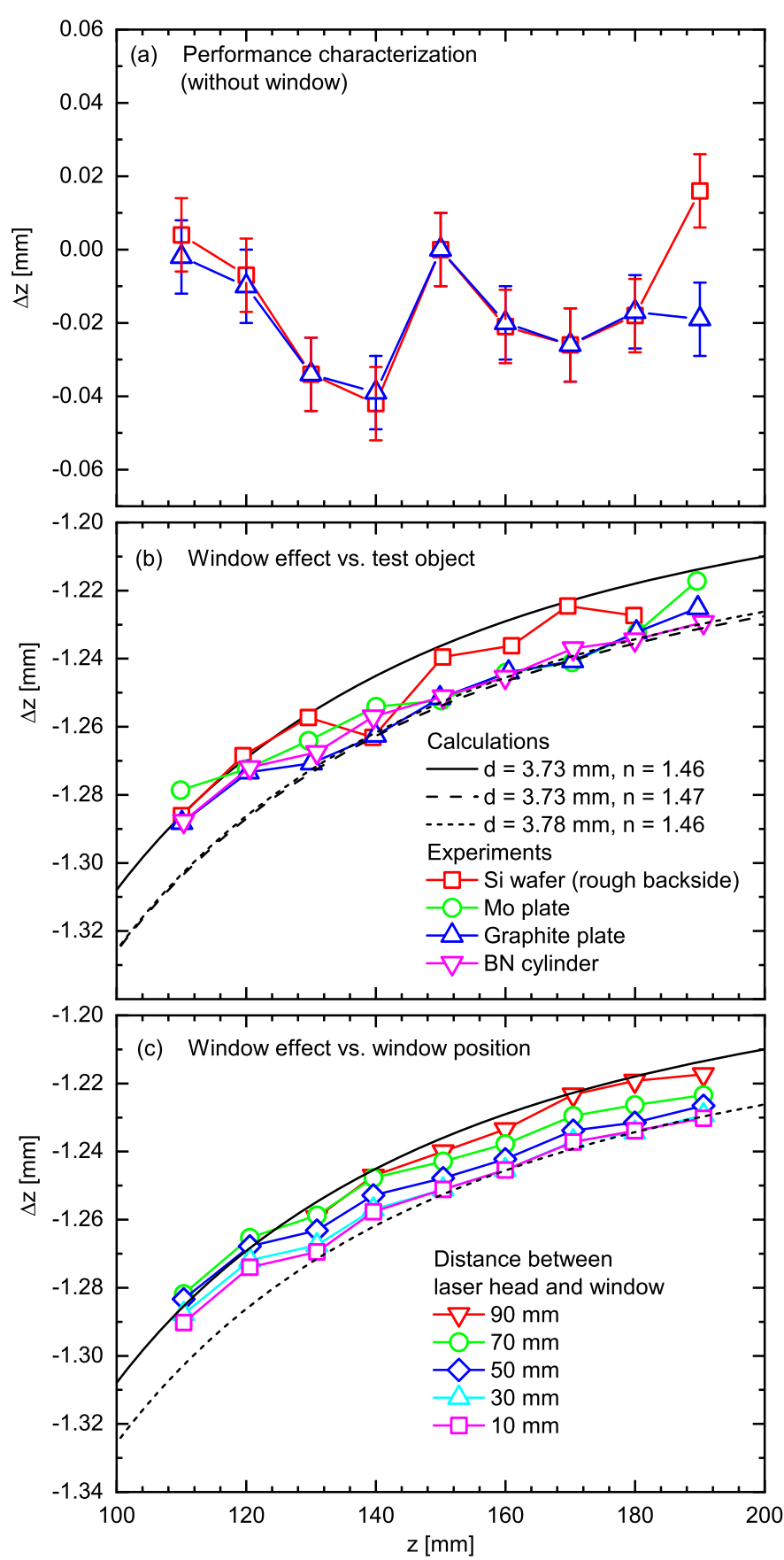

Figure 4 Performance characterization of the TLH. All data given in dependence on the set distance. Panel (a): Difference between measured distance and set distance. Panel (b): Difference of the measured distance with and without a glass window for various test object surfaces (distance between window and TLH: $30 \mathrm{~mm}$ ). Panel (c): Difference of the measured distance with and without a glass window in dependence on the distance between window and TLH (test object: graphite plate). The solid and dashed lines represent calculation results according to Eq. (2). Parameters are given in the inset of panel (b)

In Fig. 4(b) the effect of a window on the measured distance data are shown, exemplary, for a glass window and different test object surfaces. There is a monotonous shift of the distance change by the window if the object distance is varied. But there is only a small 
scattering of the data with respect to the test object. Still, a good match between experimental and calculated data can be seen.

Please note, the calculation results show that the window effect is very sensitive to the index of refraction or the thickness of the window. Changing the index of refraction by 0.01 or the thickness by $0.05 \mathrm{~mm}$ result both in a change of the measured distance by $-0.02 \mathrm{~mm}$. Therefore, a window with a reproducible index of refraction and a homogeneous thickness shall be used. Figure 4(c) illustrates that the position of the window has also a small impact on measured distance. However, this change is of less importance since the window will be mounted at a fixed position in the experimental setup for EP thruster characterization.

In order to minimize the window effect, two windows instead of one can be used: one for the incident laser beam and one for the scattered light that enters the TLH. If both windows are positioned such that the respective light enters the windows at normal incidence, refraction is eliminated. Still, to be precise, this is only true for the scattered light that is emitted at a certain distance, preferably the reference distance. Therefore, in all cases, the window effect shall be investigated carefully by experiment before using the TLH.

Furthermore, the data illustrate that different materials (silicon, molybdenum, boron nitride, or graphite) of different color (white, metallic, black) and different surface finishing (mechanically polished, chemically roughened, polycrystalline) can be measured. TLH measurements in the standard configuration (see Fig. 1) requires that the incident laser light is at least partially scattered.

In the following, the object height $h$ with respect to the reference distance $z_{\text {ref }}$ instead of the object distance $z$ is given for the TLH data. It holds

$$
h=z_{\text {ref }}-z \text {. }
$$

Thus, the curves describe the upright surface profile of the test object.

\subsection{Telemicroscope}

A telemicroscope is a high-resolution optical camera. It consists of a camera body (with a CMOS or CCD pixel sensor), an optional extension tube, and an objective lens.

Regarding its use, the following parameters are of interest:

- object area to be imaged, the so-called 'field of view' (FOV),

- lateral (or radial) resolution, which is related to the FOV per pixel (see below),

- axial resolution, which corresponds to the depth of field (DOF),

o signal-to-noise ratio, which scales with light intensity on the detector,

- compactness,

- electrical connection/feedthrough,

○ vacuum compatibility.

Concerning compactness, electrical connection, and vacuum compatibility, the same arguments as for the TLH hold (see above).

The other parameters can be, at least in parts, calculated using geometrical optics (see Fig. 5). The imaging of an optical system can be approximated by the lens equation of a thin lens [11-13]

$$
\frac{1}{f}=\frac{1}{s_{1}}+\frac{1}{s_{2}} .
$$




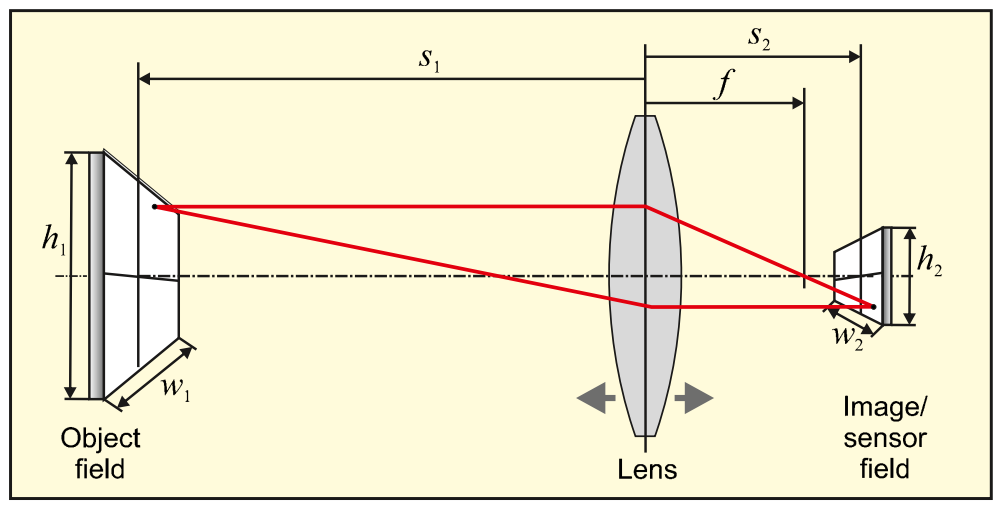

Figure 5 Schematic drawing of the imaging with a lens

$f, s_{1}$, and $s_{2}$ being the focal length, object distance, and image distance, respectively. Focusing is done by moving the lens, which is described by the lens rack out distance $\Delta s_{2}^{\text {lens }}$ $\left(s_{2}=f+\Delta s_{2}^{\text {lens }}\right)$. The maximum lens rack out distance $\Delta s_{2, \max }^{\text {lens }}$ determines the minimum distance of the focal range.

The magnification relates the field of view (object width times object height: $w_{1} \times h_{1}$ ) and the sensor size (image/sensor width times image/sensor height: $w_{2} \times h_{2}$ ). It is given by $[11-13]$

$$
M=\frac{h_{2}}{h_{1}}=\frac{w_{2}}{w_{1}} .
$$

Using the lens equation, the magnification can be written as follows

$$
M=\frac{s_{2}-f}{f} .
$$

This leads to

$$
w_{1}=w_{2} \frac{s_{2}-f}{f}=\frac{w_{2}}{s_{1}-f}
$$

and

$$
h_{1}=h_{2} \frac{s_{2}-f}{f}=\frac{h_{2}}{s_{1}-f} .
$$

The lateral (or radial) resolution of a pixel sensor depends on the pixel size. Let's consider two point sources. If they lie close to each other, they might be imaged on the same or neighboring pixels of the sensor, i.e. their images cannot be separated. However, if the spacing between the point sources is increased, they might get imaged on pixels, which are separated by at least one pixel in between (see Fig. 6).

Following that, the lateral resolution can be estimated to be the object width (or height) that corresponds to twice the image width (or height) of a pixel of the sensor. Considering a pixel sensor with $m_{\mathrm{w}} \times m_{\mathrm{h}}$ pixels, the object width $w_{1}^{\text {pix }}$ and height $h_{1}^{\text {pix }}$ that is imaged on 


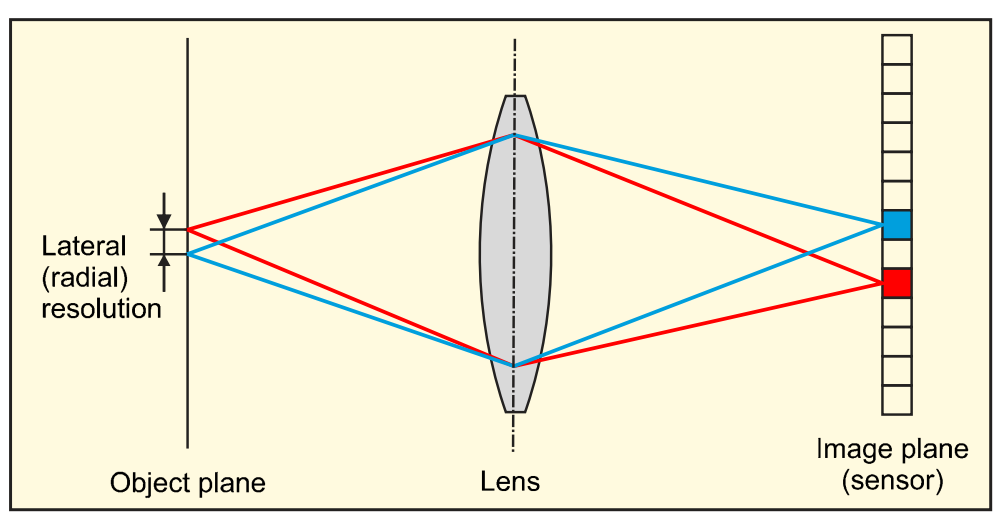

Figure 6 Illustration of the lateral resolution of an optical system with a pixel sensor (CCD/CMOS): Two point sources can be laterally resolved if their images are separated by at least one pixel

one pixel are given by

$$
\begin{aligned}
& w_{1}^{\mathrm{pix}}=\frac{w_{1}}{m_{\mathrm{w}}}=\frac{w_{2}}{m_{\mathrm{w}}} \cdot \frac{s_{2}-f}{f}=\frac{w_{2}}{m_{\mathrm{w}}\left(s_{1}-f\right)}, \\
& h_{1}^{\mathrm{pix}}=\frac{h_{1}}{m_{\mathrm{h}}}=\frac{h_{2}}{m_{\mathrm{h}}} \cdot \frac{s_{2}-f}{f}=\frac{h_{2}}{m_{\mathrm{h}}\left(s_{1}-f\right)} .
\end{aligned}
$$

The axial resolution corresponds to the depth of field (DOF), which describes the object distance range of acceptable sharpness. That is, objects lying within this range appear acceptably sharp at the image plane. The near $\left(s_{\mathrm{n}}\right)$ and far distance $\left(s_{\mathrm{f}}\right)$ of acceptable sharpness are given by [11-13]

$$
\begin{aligned}
& s_{\mathrm{n}}=\frac{s_{1}\left(s_{\mathrm{h}}-f\right)}{s_{\mathrm{h}}+s_{1}-2 f} \approx \frac{s_{1} \cdot s_{\mathrm{h}}}{s_{\mathrm{h}}+s_{1}}, \\
& s_{\mathrm{f}}=\frac{s_{1}\left(s_{\mathrm{h}}-f\right)}{s_{\mathrm{h}}-s_{1}} \approx \frac{s_{1} \cdot s_{\mathrm{h}}}{s_{\mathrm{h}}-s_{1}}
\end{aligned}
$$

$s_{1}$ and $s_{\mathrm{h}}$ are the object distance (in focus) and the hyperfocal distance, respectively. $s_{\mathrm{h}}$ defines the minimum object distance at which the range of acceptable sharpness extends to infinity $\left(s_{\mathrm{f}}=\infty\right)$. It is given by [11-13]

$$
s_{\mathrm{h}}=\frac{f^{2}}{N c_{\max }}+f \approx \frac{f^{2}}{N c_{\max }}
$$

$N$ and $c_{\max }$ are f-number and circle of confusion $(\mathrm{CoC})$, respectively. The depth of field is given by

$$
D O F=s_{\mathrm{f}}-s_{\mathrm{n}} .
$$

Point sources, which do not lie at the focal point, appear as blurred circle of diameter $c$ on the sensor. The maximum diameter, at which the blurring seems to be acceptable, is the $\mathrm{CoC}$ [11]. In this case, the point source is located within the range of acceptable sharpness (see Fig. 7). 


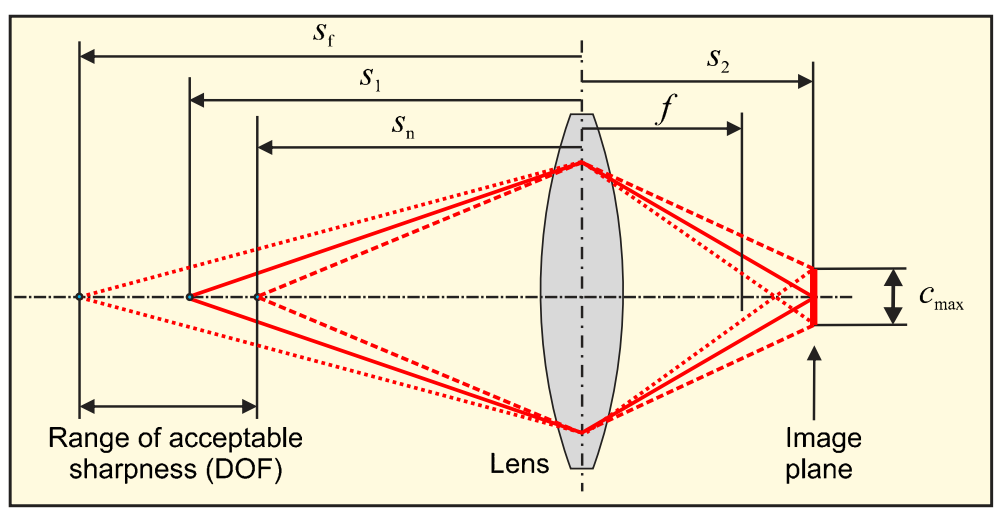

Figure 7 Illustration of the depth of field: All point sources, which lie within the distance range of acceptable sharpness, have an image diameter that is smaller or equal to the circle of confusion

The circle of confusion depends on the visual acuity, the distance at which the final image is viewed, and the enlargement of the final image [11-13]. Additionally, image contrast and illumination [12] play a role. Thus, the CoC depends on the observer and viewing conditions. Hence, any $\mathrm{CoC}$ value can only be an approximation.

Therefore and for simplicity, the $\mathrm{CoC}$ is often related to the sensor diameter. Typical values range from $1 / 1000$ to $1 / 2000$ of the sensor diameter, but in most cases $1 / 1500$ or $1 / 1730$ are stated $[14,15]$ (sometimes, unofficially called 'Zeiss formula').

Following the above given equations and statements, the performance of the telemicroscope depends on focal length, object distance, sensor size, pixel size, and f-number. According to Eq. (4), the object distance $s_{1}$ is determined by focal length $f$ and image distance $s_{2}$. As it was said before, the image distance of an optical camera is given by $f \leq s_{2} \leq f+\Delta s_{2, \max }^{\text {lens }}$. If needed, the imaging distance can be increased by insertion of an extension tube with length $l$ in between the photographic lens and the sensor

$$
s_{2}=f+l+\Delta s_{2}^{\text {lens }} .
$$

In the following calculations and experiments with an extension tube, the lens rack out distance was always set to zero $\left(\Delta s_{2, \max }=0\right)$. Focusing was done by high-precision movement of the telemicroscope relative to the test object to be imaged.

In order to illustrate the impact of the parameters, Tables 2, 3, and 4 summarize, exemplary for a telemicroscope that is used in the experiments described later, calculation results in dependence on focal length, extension tube length, and f-number, respectively.

The main conclusions can be summarized as follows

○ Focal length $f$ :

Increasing the focal length yields an increase of the object distance (= working distance), an increase of the field of view (per pixel), which corresponds to a reduction of the lateral resolution, and an increase of the depth of field (= axial resolution).

- Extension tube length $l$ :

If the length of the extension tube is increased, the working distance, the field of view (per pixel), and the depth of field become smaller. Hence, lateral and axial resolution are improved.

- Sensor size: 
Table 2 Calculated performance parameters of a telemicroscope in dependence on the focal length (extension tube length: I $=50 \mathrm{~mm}$; f-number: $N=2.8$; sensor size: $7.04 \mathrm{~mm} \times 5.28 \mathrm{~mm}$; pixel size: 4.4 $\mu \mathrm{m} \times 4.4 \mu \mathrm{m}$; circle of confusion: $c_{\max }=0.0059 \mathrm{~mm}$ )

\begin{tabular}{|c|c|c|c|c|c|c|c|c|c|c|c|}
\hline $\begin{array}{l}f \\
{[\mathrm{~mm}]}\end{array}$ & $\begin{array}{l}\mathrm{s}_{2} \\
{[\mathrm{~mm}]}\end{array}$ & $\begin{array}{l}s_{1} \\
{[\mathrm{~mm}]}\end{array}$ & $M$ & $\begin{array}{l}W_{1} \\
{[\mathrm{~mm}]}\end{array}$ & $\begin{array}{l}h_{1} \\
{[\mathrm{~mm}]}\end{array}$ & $\begin{array}{l}S_{h} \\
{[\mathrm{~m}]}\end{array}$ & $\begin{array}{l}s_{\mathrm{n}} \\
{[\mathrm{mm}]}\end{array}$ & $\begin{array}{l}s_{\mathrm{f}} \\
{[\mathrm{mm}]}\end{array}$ & $\begin{array}{l}s_{\mathrm{f}}-s_{\mathrm{n}} \\
{[\mathrm{mm}]}\end{array}$ & $\begin{array}{l}w_{1}^{\text {pix }}=h_{1}^{\text {pix }} \\
{[\mu \mathrm{m}]}\end{array}$ & $\begin{array}{l}\text { lat. res. } \\
{[\mu \mathrm{m}]}\end{array}$ \\
\hline 4 & 54.0 & 4.3 & 12.50 & 0.56 & 0.42 & 0.98 & 4.30 & 4.34 & 0.04 & 0.35 & 0.7 \\
\hline 8 & 58.0 & 9.3 & 6.25 & 1.13 & 0.84 & 3.90 & 9.26 & 9.30 & 0.04 & 0.70 & 1.4 \\
\hline 16 & 66.0 & 21.1 & 3.13 & 2.25 & 1.69 & 15.60 & 21.09 & 21.15 & 0.06 & 1.41 & 2.8 \\
\hline 25 & 75.0 & 37.5 & 2.00 & 3.52 & 2.64 & 38.07 & 37.46 & 37.54 & 0.07 & 2.20 & 4.4 \\
\hline 33 & 83.0 & 54.8 & 1.52 & 4.65 & 3.48 & 66.33 & 54.73 & 54.83 & 0.09 & 2.90 & 5.8 \\
\hline 50 & 100.0 & 100.0 & 1.00 & 7.04 & 5.28 & 152.24 & 99.93 & 100.07 & 0.13 & 4.40 & 8.8 \\
\hline 75 & 125.0 & 187.5 & 0.67 & 10.56 & 7.92 & 342.51 & 187.40 & 187.60 & 0.21 & 6.60 & 13.2 \\
\hline 100 & 150.0 & 300.0 & 0.50 & 14.08 & 10.56 & 608.87 & 299.85 & 300.15 & 0.30 & 8.80 & 17.6 \\
\hline 150 & 200.0 & 600.0 & 0.33 & 21.12 & 15.84 & 1369.87 & 599.74 & 600.26 & 0.53 & 13.20 & 26.4 \\
\hline 200 & 250.0 & 1000.0 & 0.25 & 28.16 & 21.12 & 2435.26 & 999.59 & 1000.41 & 0.82 & 17.60 & 35.2 \\
\hline
\end{tabular}

Table 3 Calculated performance parameters of a telemicroscope in dependence on the extension tube length (focal length: $f=50 \mathrm{~mm}$; $f$-number: $N=2.8$; sensor size: $7.04 \mathrm{~mm} \times 5.28 \mathrm{~mm}$; pixel size: $4.4 \mu \mathrm{m} \times 4.4 \mu \mathrm{m}$; circle of confusion: $c_{\max }=0.0059 \mathrm{~mm}$ )

\begin{tabular}{|c|c|c|c|c|c|c|c|c|c|c|c|}
\hline $\begin{array}{l}\text { I } \\
{[\mathrm{mm}]}\end{array}$ & $\begin{array}{l}s_{2} \\
{[\mathrm{~mm}]}\end{array}$ & $\begin{array}{l}s_{1} \\
{[\mathrm{~mm}]}\end{array}$ & M & $\begin{array}{l}W_{1} \\
{[\mathrm{~mm}]}\end{array}$ & $\begin{array}{l}h_{1} \\
{[\mathrm{~mm}]}\end{array}$ & $\begin{array}{l}S_{\mathrm{h}} \\
{[\mathrm{m}]}\end{array}$ & $\begin{array}{l}s_{\mathrm{n}} \\
{[\mathrm{mm}]}\end{array}$ & $\begin{array}{l}s_{\mathrm{f}} \\
{[\mathrm{mm}]}\end{array}$ & $\begin{array}{l}s_{\mathrm{f}}-s_{\mathrm{n}} \\
{[\mathrm{mm}]}\end{array}$ & $\begin{array}{l}w_{1}^{\text {pix }}=h_{1}^{\text {pix }} \\
{[\mu \mathrm{m}]}\end{array}$ & $\begin{array}{l}\text { lat. res. } \\
{[\mu \mathrm{m}]}\end{array}$ \\
\hline 1.0 & 51.0 & 2550.0 & 0.02 & 352.00 & 264.00 & 152.24 & 2507.99 & 2593.44 & 85.45 & 220.00 & 440.0 \\
\hline 2.0 & 52.0 & 1300.0 & 0.04 & 176.00 & 132.00 & 152.24 & 1288.99 & 1311.20 & 22.20 & 110.00 & 220.0 \\
\hline 5.0 & 55.0 & 550.0 & 0.10 & 70.40 & 52.80 & 152.24 & 548.02 & 551.99 & 3.97 & 44.00 & 88.0 \\
\hline 10.0 & 60.0 & 300.0 & 0.20 & 35.20 & 26.40 & 152.24 & 299.41 & 300.59 & 1.18 & 22.00 & 44.0 \\
\hline 25.0 & 75.0 & 150.0 & 0.50 & 14.08 & 10.56 & 152.24 & 149.85 & 150.15 & 0.30 & 8.80 & 17.6 \\
\hline 50.0 & 100.0 & 100.0 & 1.00 & 7.04 & 5.28 & 152.24 & 99.93 & 100.07 & 0.13 & 4.40 & 8.8 \\
\hline 75.0 & 125.0 & 83.3 & 1.50 & 4.69 & 3.52 & 152.24 & 83.29 & 83.38 & 0.09 & 2.93 & 5.9 \\
\hline 100.0 & 150.0 & 75.0 & 2.00 & 3.52 & 2.64 & 152.24 & 74.96 & 75.04 & 0.07 & 2.20 & 4.4 \\
\hline 150.0 & 200.0 & 66.7 & 3.00 & 2.35 & 1.76 & 152.24 & 66.64 & 66.70 & 0.06 & 1.47 & 2.9 \\
\hline 200.0 & 250.0 & 62.5 & 4.00 & 1.76 & 1.32 & 152.24 & 62.47 & 62.53 & 0.05 & 1.10 & 2.2 \\
\hline
\end{tabular}

Table 4 Calculated performance parameters of a telemicroscope in dependence on the f-number (focal length: $f=50 \mathrm{~mm}$; extension tube length: I = $50 \mathrm{~mm}$; sensor size: $7.04 \mathrm{~mm} \times 5.28 \mathrm{~mm}$; pixel size: $4.4 \mu \mathrm{m} \times 4.4 \mu \mathrm{m}$; circle of confusion: $c_{\max }=0.0059 \mathrm{~mm}$ )

\begin{tabular}{rlllllllllll}
\hline$N$ & $\begin{array}{l}s_{2} \\
{[\mathrm{~mm}]}\end{array}$ & $\begin{array}{lllllll}s_{1} \\
{[\mathrm{~mm}]}\end{array}$ & $M$ & $\begin{array}{l}w_{1} \\
{[\mathrm{~mm}]}\end{array}$ & $\begin{array}{l}h_{1} \\
{[\mathrm{~mm}]}\end{array}$ & $\begin{array}{l}s_{h} \\
{[\mathrm{~m}]}\end{array}$ & $\begin{array}{l}s_{\mathrm{n}} \\
{[\mathrm{mm}]}\end{array}$ & $\begin{array}{l}s_{\mathrm{f}} \\
{[\mathrm{mm}]}\end{array}$ & $\begin{array}{l}s_{\mathrm{f}}-s_{n} \\
{[\mathrm{~mm}]}\end{array}$ & $\begin{array}{l}w_{1}^{\text {pix }}=h_{1}^{\text {pix }} \\
{[\mu \mathrm{m}]}\end{array}$ & $\begin{array}{l}\text { lat. res. } \\
{[\mu \mathrm{m}]}\end{array}$ \\
\hline 1.0 & 100.0 & 100.0 & 1.00 & 7.04 & 5.28 & 426.19 & 99.98 & 100.02 & 0.05 & 4.40 & 8.8 \\
1.4 & 100.0 & 100.0 & 1.00 & 7.04 & 5.28 & 304.43 & 99.97 & 100.03 & 0.07 & 4.40 & 8.8 \\
2.0 & 100.0 & 100.0 & 1.00 & 7.04 & 5.28 & 213.12 & 99.95 & 100.05 & 0.09 & 4.40 & 8.8 \\
2.8 & 100.0 & 100.0 & 1.00 & 7.04 & 5.28 & 152.24 & 99.93 & 100.07 & 0.13 & 4.40 & 8.8 \\
4.0 & 100.0 & 100.0 & 1.00 & 7.04 & 5.28 & 106.58 & 99.91 & 100.09 & 0.19 & 4.40 & 8.8 \\
5.6 & 100.0 & 100.0 & 1.00 & 7.04 & 5.28 & 76.15 & 99.87 & 100.13 & 0.26 & 4.40 & 8.8 \\
8.0 & 100.0 & 100.0 & 1.00 & 7.04 & 5.28 & 53.32 & 99.81 & 100.19 & 0.38 & 4.40 & 8.8 \\
11.0 & 100.0 & 100.0 & 1.00 & 7.04 & 5.28 & 38.79 & 99.74 & 100.26 & 0.52 & 4.40 & 8.8 \\
16.0 & 100.0 & 100.0 & 1.00 & 7.04 & 5.28 & 26.68 & 99.63 & 100.38 & 0.75 & 4.40 & 8.8 \\
22.0 & 100.0 & 100.0 & 1.00 & 7.04 & 5.28 & 19.42 & 99.49 & 100.52 & 1.03 & 4.40 & 8.8 \\
\hline
\end{tabular}

Increasing the sensor size results in an increase of the field of view (per pixel) and, thus, in a reduction of the lateral resolution. Furthermore, the circle of confusion gets larger and, hence, the axial resolution gets larger.

○ Pixel size:

The pixel size affects the field of view per pixel and, hence, the lateral resolution. If the pixel size gets larger, the lateral resolution is increased. 

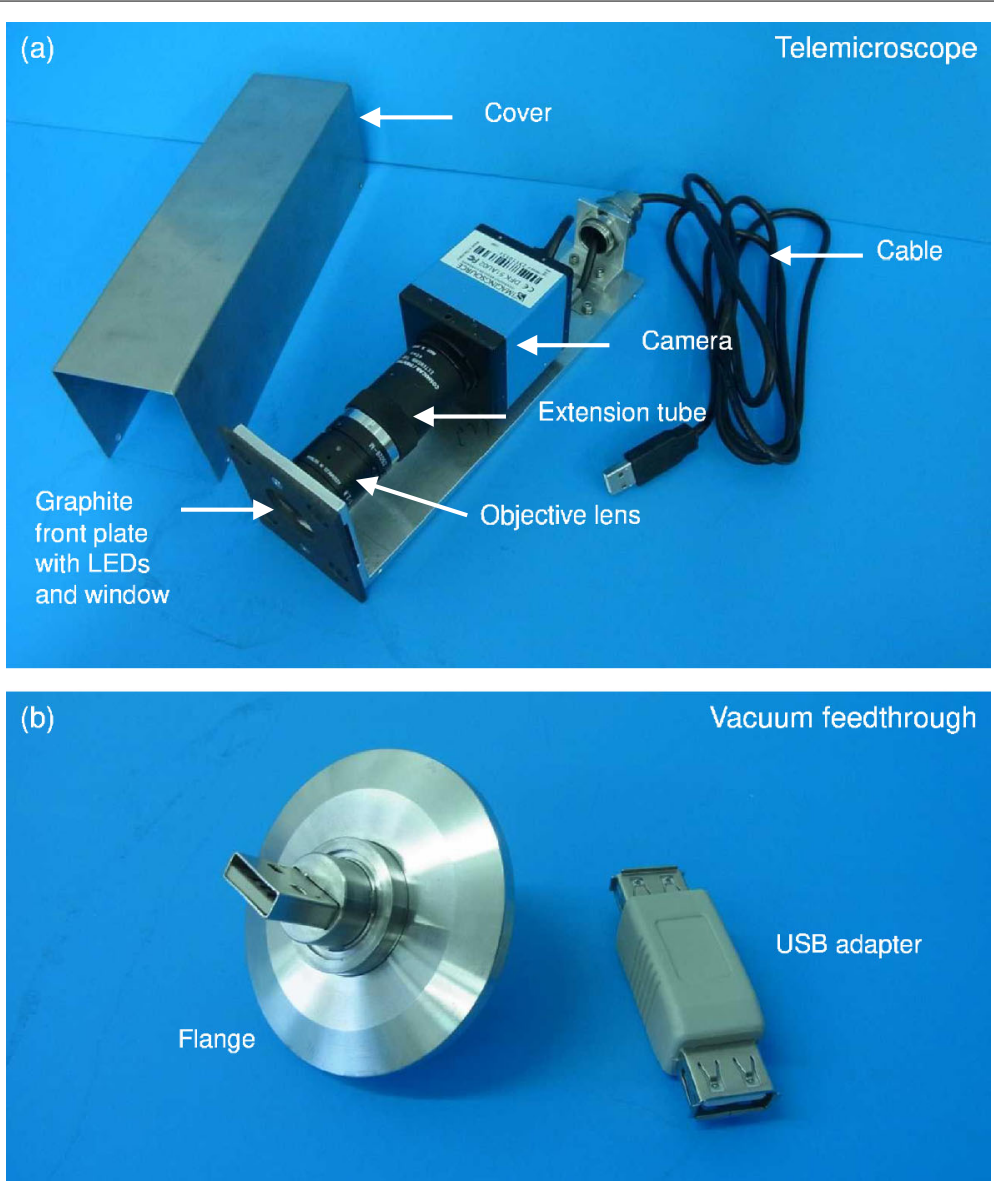

Figure 8 Experimental setup for in situ telemicroscope measurements: telemicroscope with housing (a) and vacuum feedthrough with adapter (b)

\section{○ F-number:}

The f-number has only an impact on the depth of field. If the f-number becomes larger, the depth of field increases and, thus, the axial resolution gets worse.

The signal-to-noise ratio should be as high as possible in order to improve the image quality. It gets larger if more light falls onto a pixel of the sensor. Therefore, decreasing the f-number, increasing the field of view per pixel or the intensity of the illumination light yields a better signal-to-noise ratio. It also depends on the properties of the test object, namely the amount of light that is reflected or scattered off the object surface: The lighter the object, the more light gets off the sample.

There are many cameras and objective lenses of different size and with different parameters commercially available. Exemplary, an experimental setup with an USB camera DFK 51AU02 (The Imaging Source; dimension: $50.6 \mathrm{~mm} \times 50.6 \mathrm{~mm} \times 56 \mathrm{~mm}$ ) with an extension tube and an objective lens C5028-M (Pentax; diameter: $29.5 \mathrm{~mm}$; length: $34.0 \mathrm{~mm}$ ) is shown in Fig. 8.

The telemicroscope is covered by a metal housing (dimension: $60 \mathrm{~mm} \times 70 \mathrm{~mm} \times$ $210 \mathrm{~mm}$ ) for EP thruster characterization campaigns. The setup uses a graphite front plate, a sapphire window, four high-power LEDs for illumination (not shown in Fig. 8), and an commercial USB vacuum feedthrough. 

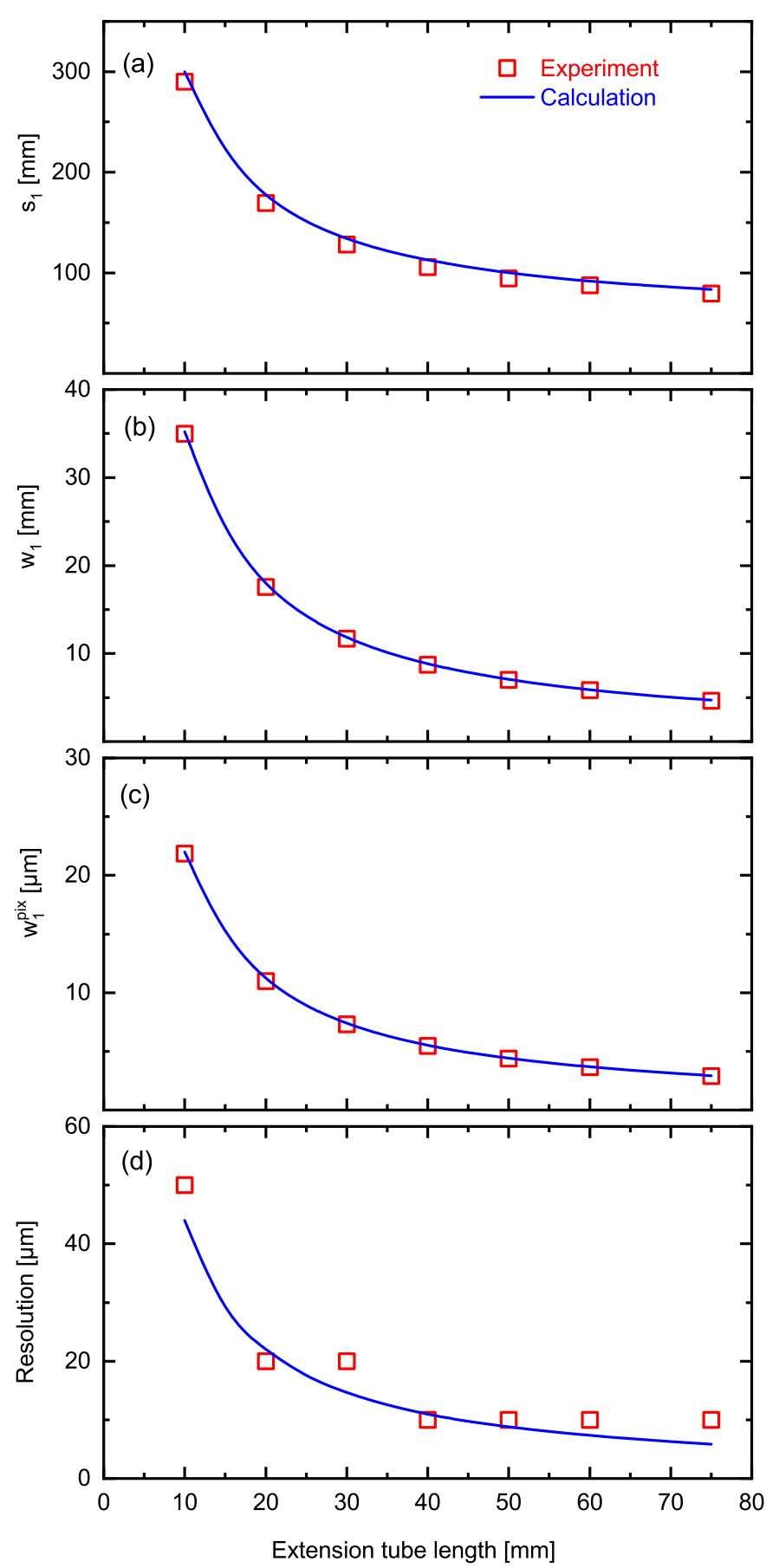

Figure 9 Experimental (red squares) and calculated (blue lines) performance parameters of a telemicroscope in dependence on the extension tube length: object distance (a), total horizontal field of view (b), horizontal field of view per pixel (c), and lateral resolution (d). (Sensor resolution: $1600 \times 1200$ pixels; sensor size: $7.04 \mathrm{~mm} \times 5.28 \mathrm{~mm}$; pixel size: $4.4 \mu \mathrm{m} \times 4.4 \mu \mathrm{m}$; focal length: $f=50 \mathrm{~mm}$; f-number: $N=2.8$ )

Experimental data in dependence on the extension tube length are compared with calculation results (see Table 3) in Fig. 9. Calculations are based on the following parameters: The camera has a sensor size of $7.04 \mathrm{~mm} \times 5.28 \mathrm{~mm}$ with a resolution of $1600 \mathrm{x} 1200$ pix- 
(a)

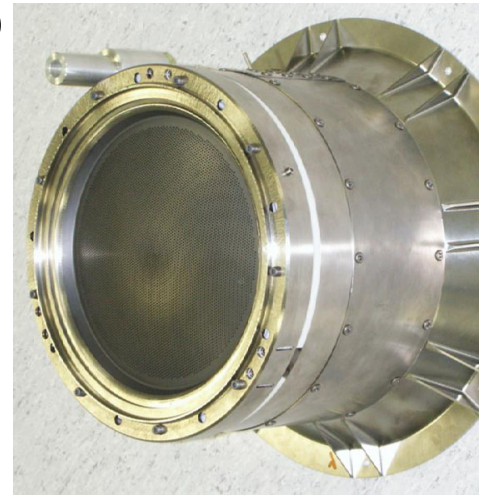

(b)

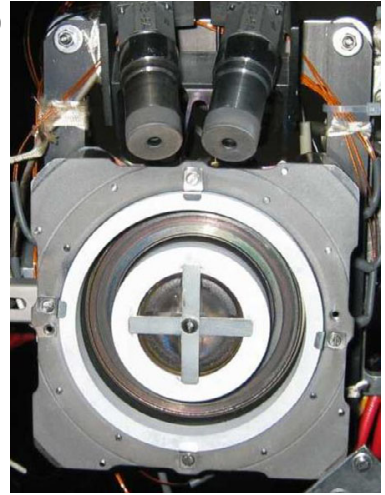

Figure 10 Images of a RIT-22 (a) and the SPT-100D before the tests (b)

els and a pixel size of $4.4 \mu \mathrm{m} \times 4.4 \mu \mathrm{m}$. The focal length of the objective lens is $50 \mathrm{~mm}$. The lens allows f-numbers ranging from $N=2.8$ up to $N=22$. The f-number was set to $N=2.8$ in order to maximize the light intensity on the sensor and minimize the depth of field.

The experimental data were evaluated using two test structures: an eyepiece graticule for measuring the FOV and a laser-scribed line structure for characterizing the lateral resolution. Test structures and test procedures are described elsewhere [2]. There is a very good agreement between experimental and calculated data.

The telemicroscope images in Sect. 3 were recorded with a different setup. It uses a camera DMK 41AF02 (The Imaging Source) with a sensor size of $5.95 \mathrm{~mm} \times 4.46 \mathrm{~mm}$, a resolution of $1280 \times 960$ pixels, and a pixel size of $4.65 \mu \mathrm{m} \times 4.65 \mu \mathrm{m}$. The objective lens has a focal length of $f=135 \mathrm{~mm}$ and a f-number range from $N=2.8$ up to $N=16$. An extension tube length of $l=150 \mathrm{~mm}$ was used. This setup allows a larger object distance of $s_{1}=256.5 \mathrm{~mm}$ while keeping a high lateral resolution of $8.4 \mu \mathrm{m}$ and a small DOF of $\sim 0.1 \mathrm{~mm}$.

As it was said before, the calculated depth of field is an approximation, because it depends on the observer and viewing conditions. Performance characterization experiments with the test line structure yield results close to that. However, these measurements resemble the ideal case, i.e. high optical contrast, sharp and straight edges, flat and smooth object surface, and surface aligned perpendicular to the center axis of the TMS. In the experiments with the thrusters these ideal conditions can often not be fulfilled. Therefore, the achievable axial resolution is estimated to be not better than $0.5 \mathrm{~mm}$.

For completeness, there is a different approach for erosion measurements with a telemicroscope $[3,4]$ : A laser line is projected on the region of interest and imaged. By applying a $3 \mathrm{D}$ reconstruction algorithm, the surface profile can be obtained from the shape of the laser line projection. Misuri et al. reported accurate erosion data for the channel wall erosion of a Hall effect thruster, which was operated with different channel wall materials (boron nitride, Macor, Shapal) [3]. Telemicroscope results were verified by caliper measurements. Andreussi et al. used the setup to study the erosion of a high-power Hall effect thruster [4]. A very good agreement with profilometer measurements was reported.

\subsection{Vacuum test facility and test objects}

Thruster test campaigns with the TLH and telemicroscope were performed in the large vacuum test facility (Aerospazio Tecnologie s.r.l.), which has a length of $11.5 \mathrm{~m}$, a diameter 

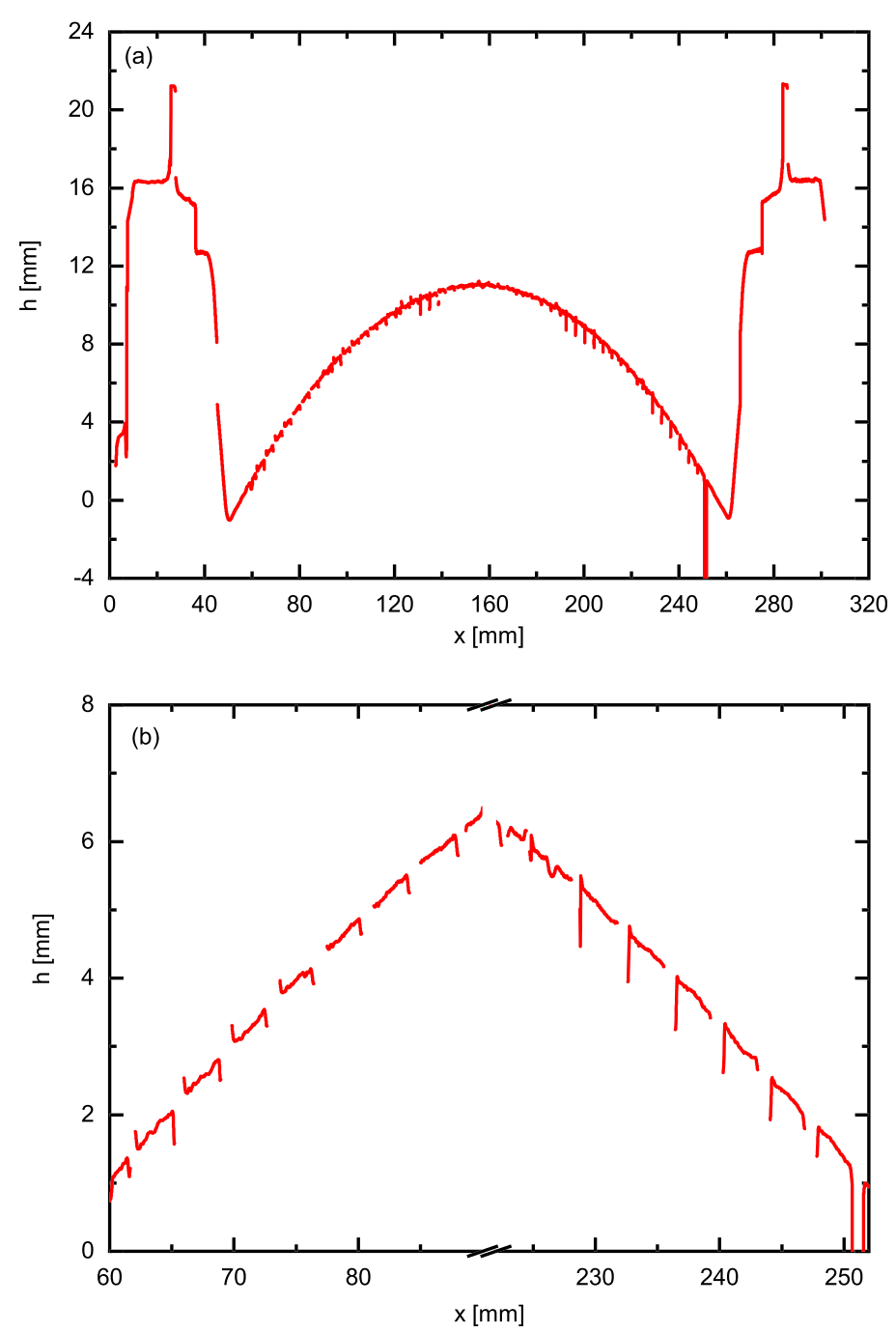

Figure 11 TLH scan across the diameter of the RIT-22: full scan (a) and enlarged details (b)

of $3.8 \mathrm{~m}$, and a volume of $120 \mathrm{~m}^{3}$. The effective pumping speed is up to $\sim 200,000 \mathrm{l} / \mathrm{s}(\mathrm{Xe})$, the ultimate base pressure is about $8 \times 10^{-8} \mathrm{mbar}$, and the operation pressure is about $4 \times$ $10^{-6}$ mbar at $40 \mathrm{sccm}$ Xe.

The first test object was a gridded ion thruster RIT-22 (ArianeGroup, see Fig. 10(a), $[8,9])$ with a grid diameter of $22 \mathrm{~cm}$. The RIT-22 is an advanced radio-frequency ion propulsion thruster/engine designed to meet the requirements of commercial and scientific missions. In this study, the thruster was operated at power levels between $1.25 \mathrm{~kW}$ (beam voltage: $1250 \mathrm{~V}$; beam current: $1000 \mathrm{~mA}$ ) and $4 \mathrm{~kW}$ (beam voltage: $2000 \mathrm{~V}$; beam current: $2000 \mathrm{~A}$ ). The total operation time for the tests was about 50 hours.

The second test object was an engineering model of a Hall Effect thruster SPT-100D (JSC EDB Fakel, see Fig. 10(b), [10]). The thruster is especially designed for high specific impulse operation. It is equipped with two hollow cathodes. The thruster was operated for about 300 hours at different power levels ranging from $1350 \mathrm{~W}$ to $1950 \mathrm{~W}$. 


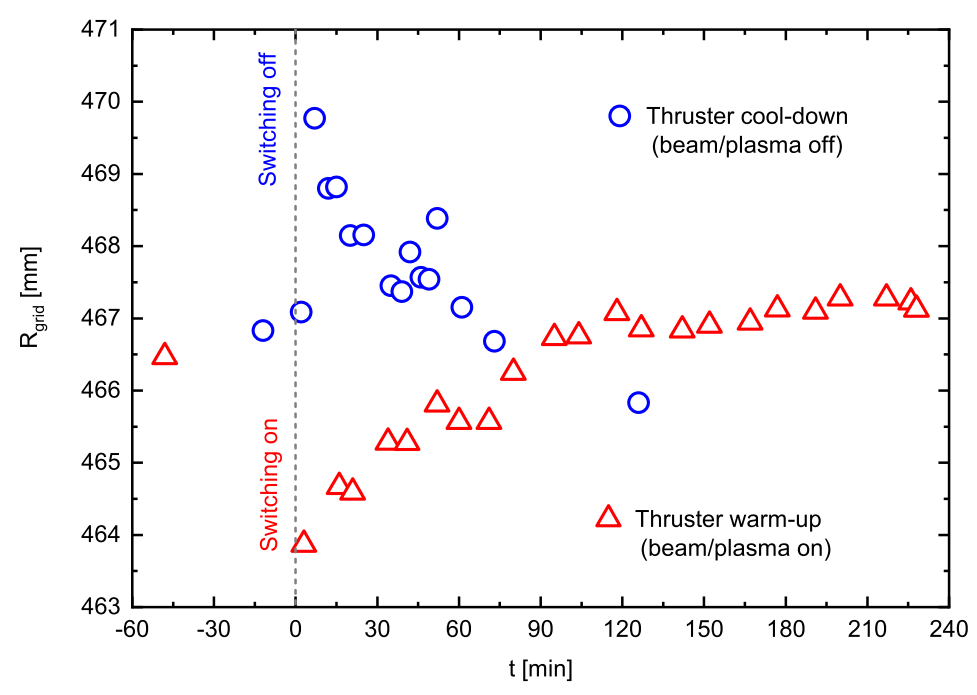

Figure 12 Grid curvature versus operation time for the warm-up phase (red triangles) and cool-down phase (blue circles) of the RIT-22. Before switching the beam on, the plasma was burning for about 2 hours. (Thruster power level: $1.25 \mathrm{~kW}$ )

There are also selected data available for a miniaturized gridded ion thruster RIT- $\mu \mathrm{X}$ (ArianeGroup, $[2,16])$.

\section{Results and discussion}

\subsection{TLH measurements with the RIT-22}

Figure 11 shows a TLH scan across the diameter of the RIT-22. The grid hole area, rim of the grid, and mounting ring can be clearly identified.

A closer look reveals the following artifacts of the TLH measurements:

- Depending on the slope of the profile, the TLH cannot measure the distance, which is the reason for the missing data points, for instance, at $x \approx 40 \mathrm{~mm}$ and $x>300 \mathrm{~mm}$ in Fig. 11(a). This is related to the fact that light, which is usually detected, is blocked by the test object if the slope of the surface is steeper than the detection angle $\alpha$. In this case, no scattered light can reach the detector.

- At sharp edges, as, for instance, at the grid hole edges, upward or downward spikes appear (see Fig. 11(b)). Again, this depends on the slope of the surface. This is related to a different scattering characteristics in comparison to a flat surface.

As a consequence, the TLH cannot measure grid hole erosion. However, the data give access to the grid curvature of the outer grid. Figure 12 summarizes grid curvature data for the warm-up and cool-down phase of the RIT-22. Please note, TLH scans during the warm-up phase were done with a firing thruster, i.e. the TLH was moved through the ion beam several times.

It can be seen that switching on the beam results in a sudden drop of the grid curvature, which was tentatively assigned to the electrostatic forces between the grids due to the switched-on high voltages [7]. With increasing operation time, the grid curvature steadily increases and reaches a stable value after about two hours [5, 7]. This reflects thermal expansion and thermal equilibrium, respectively. As the thruster is switched off, the behavior is the opposite: the grid curvature increases suddenly and steadily decreases with increasing cool-down time. 

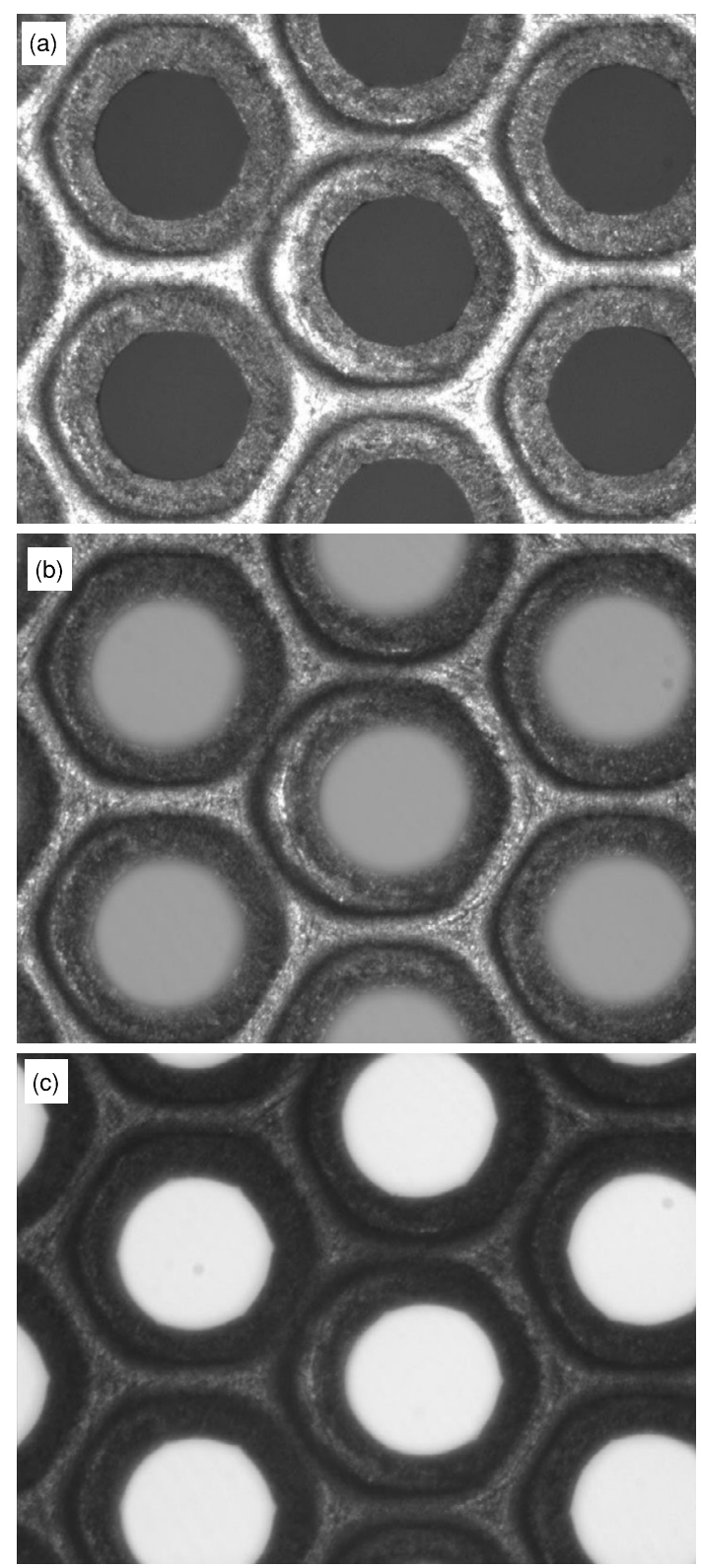

Figure 13 Telemicroscope images of grid holes of the RIT-22 at different operation stages: thruster off (a), plasma on (b), and beam on (c)

\subsection{Telemicroscope imaging of the RIT-22}

Telemicroscope images of the grid holes of the RIT-22 are given in Fig. 13. Images at different operation stages are shown. The grid holes can clearly be resolved if the thruster is switched off (Fig. 13(a)). If the plasma or the beam is on, the edges of the grid holes are blurred. This is related to light from the plasma, that is scattered at the grid hole edges. That means, precise grid erosion measurements can be done only if the thruster is switched-off. 


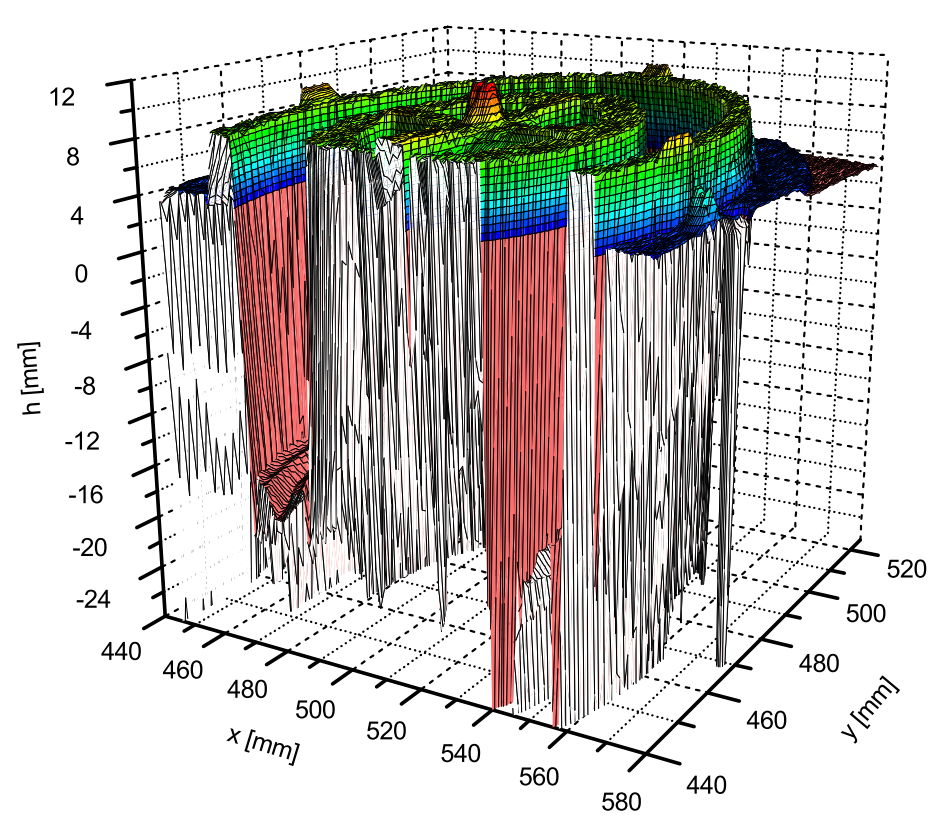

Figure 14 Section of a full TLH mapping of the SPT-100D

\subsection{TLH measurements with the SPT-100D}

Figure 14 shows a section of a full TLH mapping of the SPT-100D, which was obtained by combining about 150 linescans in $x$-direction with a shift of $\Delta y=1 \mathrm{~mm}$. All characteristic features can be identified: ceramic channel wall rings, anode layer ring at the bottom of the channels, springs and center screw for fixing the ceramic rings at the top.

Selected horizontal TLH linescans across the center of the SPT-100D and radial erosion data are summarized in Fig. 15. The full line scans show again what was already described above for the TLH measurements with the RIT-22: If the edges become too steep, the TLH measurement fails. The detailed view at the top of edge of a channel wall (see Fig. 15(b)) reveals a continuous erosion of the channel wall, at the beginning in radial and axial direction. At a certain point, axial erosion stops and only radial erosion proceeds. Numbers of the radial erosion versus thruster operation time are plotted in Fig. 15(c).

\subsection{Telemicroscope imaging of the SPT-100D}

Selected telemicroscope images of the SPT-100D are shown in Figs. 16 and 17. Figure 16 illustrates the increasing radial erosion versus operation time. Radial erosion data from the telemicroscope images agree well with data from the TLH measurements (see Sect. 3.3).

Additionally, the surface modification can be seen. The top face of the channel wall changes from a flat appearance with grooves from mechanical grinding to a more grainy structure. In contrast to that, the area next to the channel wall becomes brighter, which indicates a coating or polishing.

The axial erosion is illustrated by the telemicroscope images in Fig. 17. By moving the thruster closer to the telemicroscope, the focal point moves steadily from top of the channel wall along the eroded slope. Again, considering the higher uncertainty of $\pm 0.5 \mathrm{~mm}$, the numbers agree well with those from TLH measurements. 

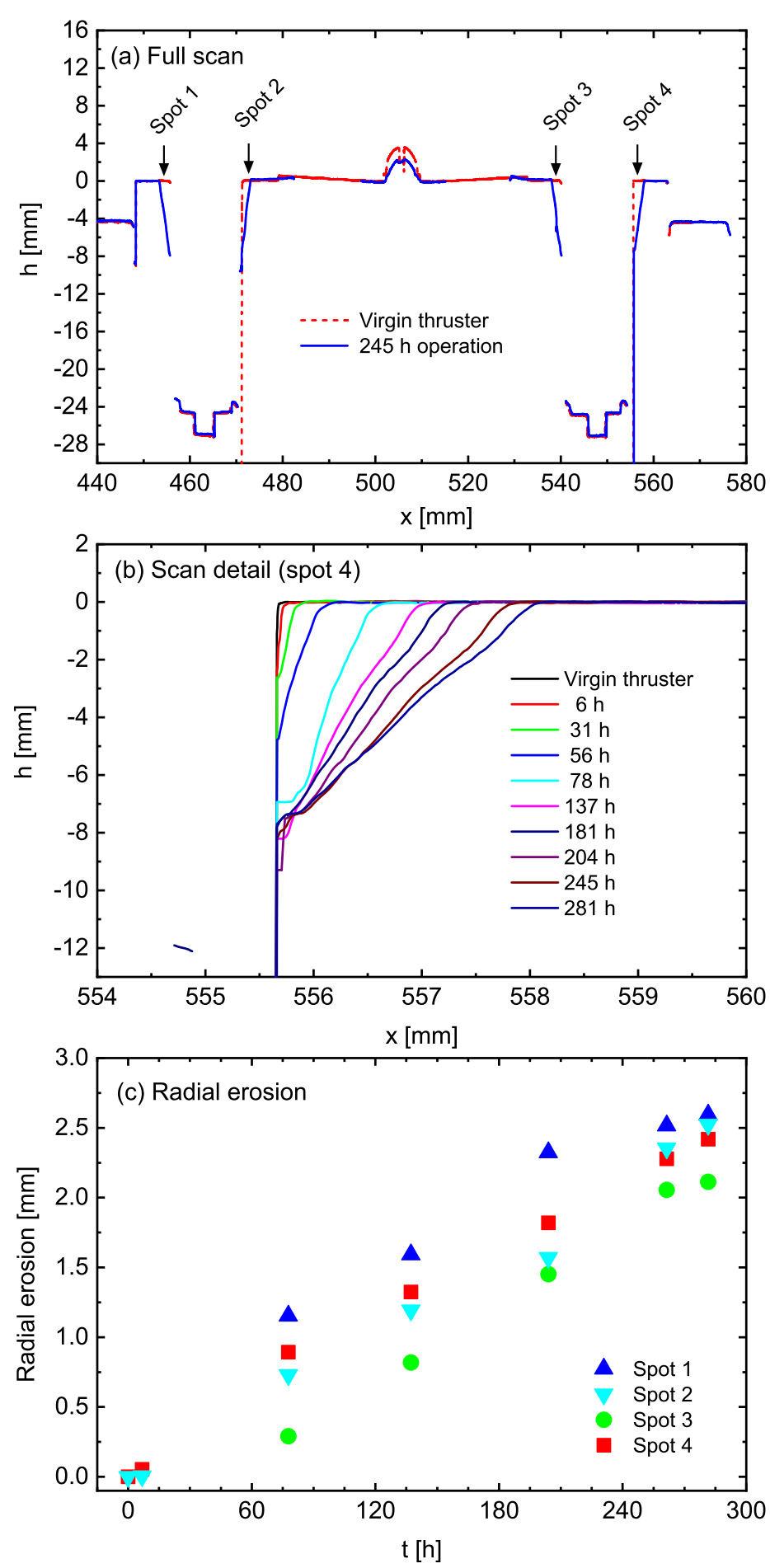

Figure 15 Horizontal TLH linescans across the center of the SPT-100D: full line scans at two operation times (a), scan detail of measurement spot 4 for several operation times (b), and extracted radial erosion data versus operation time (c) 

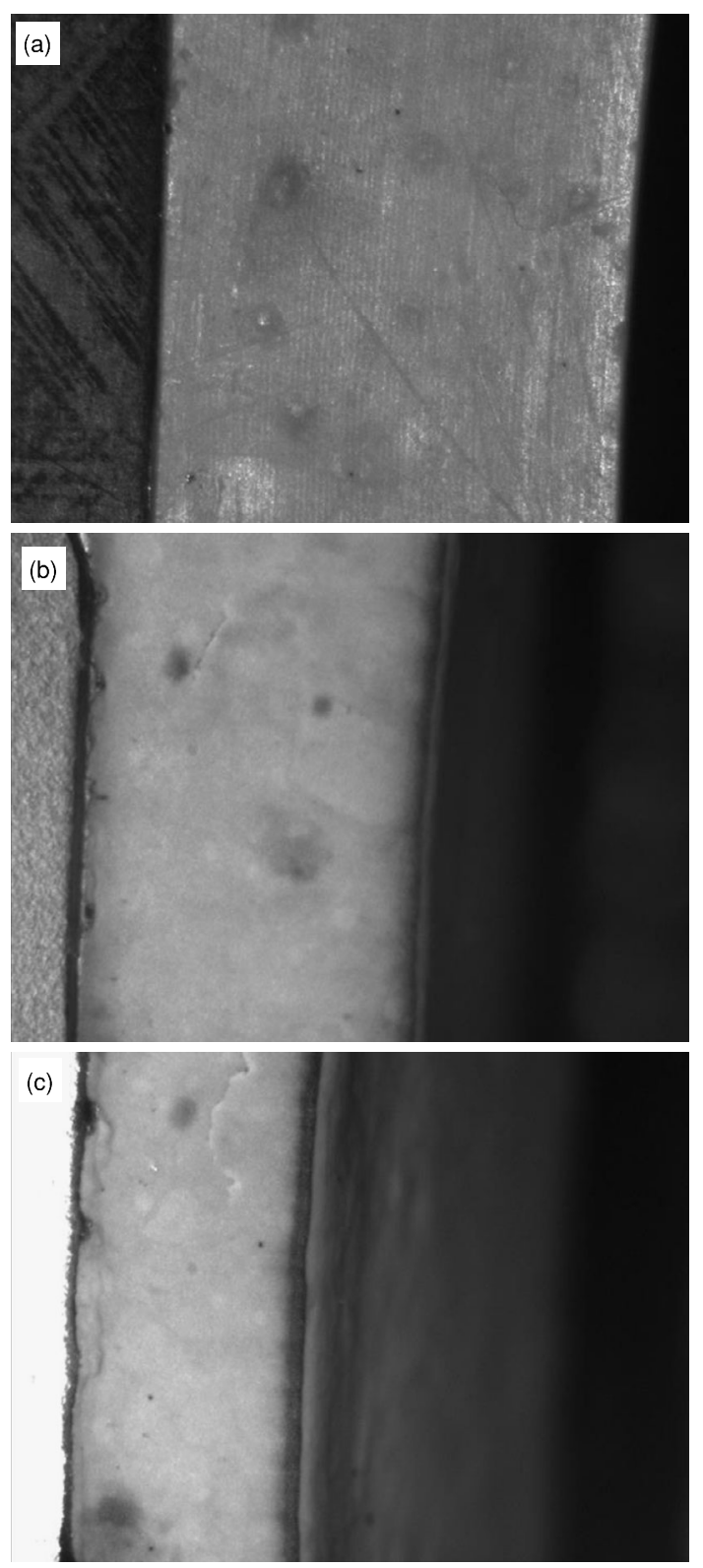

Figure 16 Telemicroscope images of the top face of a channel wall of the SPT-100D at different operation times: before test (a), after about 137 hours (b), and after about 300 hours of operation (c)

\section{Conclusions}

This work reports on the use of triangular laser heads and telemicroscopes for in situ erosion measurements of EP thruster components. The fundamentals of both techniques are described in detail. Exemplary, selected experimental setups and their performance characterization is described and critically discussed.

The capabilities and limitations of the TLH and the telemicroscope for in situ erosion measurements were investigated using, exemplary, a gridded ion thruster RIT-22 and a Hall effect thruster SPT-100D. Both techniques can give access to lateral and axial erosion. However, the strength of the telemicroscope is the determination of the radial erosion of 

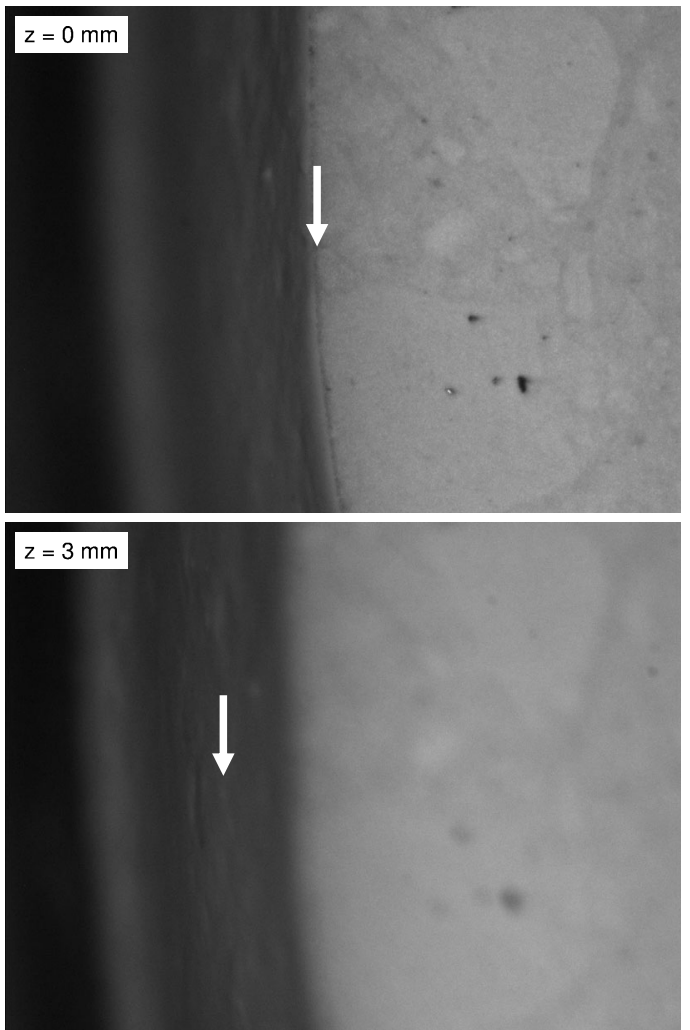

$$
\mathrm{z}=6 \mathrm{~mm}
$$

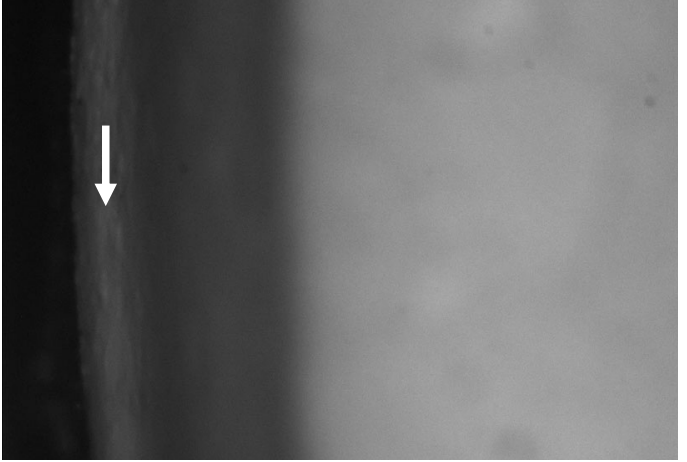

$z=8 \mathrm{~mm}$

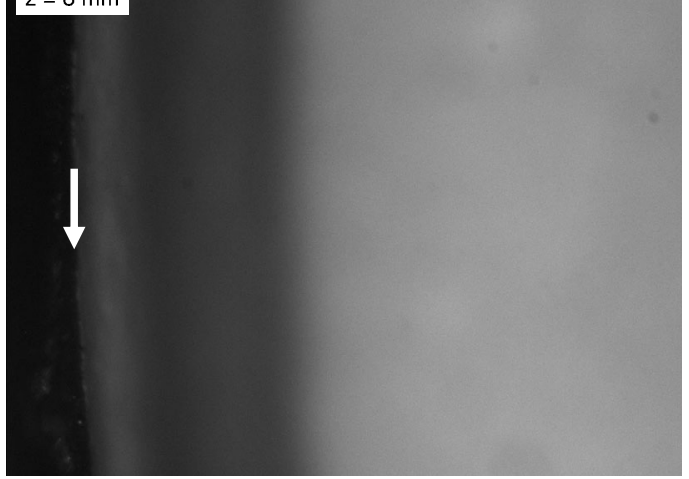

Figure 17 Telemicroscope images of a channel wall edge of the SPT-100D at different object distances. As indicated by arrows, the focal point moves along the eroded slope. Images were taken after about 300 hours of operation 
flat surfaces. Axial erosion with reduced accuracy can be accessed by exploitation of the depth of field. If it comes to 3D surfaces, TLH measurements can provide accurate radial and axial erosion data. However, if steep edges need to be measured, the orientation of the TLH with respected to the edges must be chosen carefully in order to avoid or reduce measurement artifacts.

We believe that this work is of great help for the EP community because testing is a key stage in the development of EP thrusters. Erosion data of selected mechanical parts of the thruster are important since erosion limits thruster lifetime. The tools described here can be operated in situ, i.e. inside a harsh vacuum test environment, which can help to reduce testing time and costs considerably. Extensive testing with thrusters of different types and sizes throughout the last years showed stable and reproducible operation.

\section{Acknowledgements}

Technical support by B. Faust, M. Müller, R. Woyciechowski (all IOM), the IOM workshop, R. Kukies (ArianeGroup), E. Bonelli, and S. Scaranzin (both Aerospazio Tecnologie s.r.l.) is gratefully acknowledged. We also thank our project coordinators A. Bulit, K. Dannenmayer, P.-E. Frigot, and J. González del Amo at ESA/ESTEC.

\section{Funding}

The authors are grateful for financial support provided by ESA/ESTEC (contracts No. 20461/06/NL/CP and No. 4000107451/12/NL/RA). Open Access funding enabled and organized by Projekt DEAL.

\section{Abbreviations}

CoC, circle of confusion; DOF, depth of field; FOV, field of view; EP, electric propulsion; RIT, radio-frequency ion thruster; SPT, stationary plasma thruster; TLH, Triangular laser head; AEPD, advanced electric propulsion diagnostic (platform).

\section{Availability of data and materials}

The data sets used and/or analyzed during the current study are available from the corresponding author on reasonable request.

\section{Declarations}

Ethics approval and consent to participate

Not applicable.

Consent for publication

All authors agree to the publication of the article.

Competing interests

The authors declare that they have no competing interests.

Authors' contributions

$\mathrm{CB}, \mathrm{MT}, \mathrm{FS}$, and HN designed the experimental setups. All authors were involved in the diagnostics performance testing, in situ thruster characterization, or data evaluation, contributed to the preparation of the manuscript, and have read and approved the final version.

\section{Author details}

${ }^{1}$ Tools Unit, Leibniz Institute of Surface Engineering (IOM), Leipzig, Germany. ${ }^{2}$ ArianeGroup GmbH, Lampoldshausen, Germany. ${ }^{3}$ Design Department, JSC Engineering Design Bureau Fakel, Kaliningrad, Russia. ${ }^{4}$ Aerospazio s.r.l., Rapolano Terme, Italy.

\section{Publisher's Note}

Springer Nature remains neutral with regard to jurisdictional claims in published maps and institutional affiliations.

Received: 3 November 2021 Accepted: 13 January 2022 Published online: 08 February 2022

\section{References}

1. Bundesmann C, Tartz M, Scholze F, Leiter HJ, Scortecci F, Gnizdor RY, Neumann H. Note: an advanced in situ diagnostic system for characterization of electric propulsion thrusters and ion beam sources. Rev Sci Instrum. 2010;81(4):046106. https://doi.org/10.1063/1.3386585.

2. Bundesmann C, Eichhorn C, Scholze F, Spemann D, Neumann H, Pagano D, Scaranzin S, Scortecci F, Leiter HJ, Gauter S, Wiese R, Kersten H, Holste K, Köhler P, Klar PJ, Mazouffre S, Blott R, Bulit A, Dannenmayer K. An advanced electric propulsion diagnostic (AEPD) platform for in-situ characterization of electric propulsion thrusters and ion beam sources. Eur Phys J C. 2016;70:212. https://doi.org/10.1140/epjd/e2016-70236-0. 
3. Misuri T, Vrebosch T, Pieri L, Andrenucci M, Tordi M, Marcuzzi E, Bartolozzi M, Renzetti S, González del Amo J. Telemicroscopy and Thermography Diagnostic Systems for Monitoring Hall Effect Thrusters. In: 32nd International Electric Propulsion Conference (IEPC), Wiesbaden, Germany. 2011. IEPC-2011-129

4. Andreussi T, Pieri L, Albertoni R, Andrenucci M, Duchemin O. Telemicroscopy Erosion Measurements of $5 \mathrm{~kW}-\mathrm{Class}$ Hall Effect Thruster Channel Walls. In: 34th International Electric Propulsion Conference (IEPC), Hyogo-Kobe, Japan. 2015. IEPC-2015-348

5. Yuan J, Dai P, Liang D, Zhou S, Xiao S, Liang X. Grid deformation real-time measurement system of ion thruster based on videometrics. Appl Sci. 2019;9:1759. https://doi.org/10.3390/app9091759.

6. Arkhipov BA, Gnizdor RY, Maslennikov NA, Morozov Al. Anomalous erosion of dielectric under the influence of plasma flow. Sov J Plasma Phys. 1992;18(9):1241-4

7. Bundesmann C, Tartz M, Scholze F, Neumann H, Leiter HJ, Scortecci F. In situ thermal characterization of the accelerator grid of an ion thruster. J Propuls Power. 2011;27:532-7. https://doi.org/10.2514/1.50049.

8. Leiter H, Kukies R, Killinger R, Bonelli L, Scaranzin S, Scortecci F, Neumann H, Tartz M. RIT-22 Ion Propulsion System: 5000h Endurance Test Results and Life Prediction. In: 43rd AIAA/ASME/SAE/ASEE Joint Propulsion Conference \& Exhibit. 2007. AIAA 2007-5198. https://doi.org/10.2514/6.2007-5198

9. Leiter HJ, Kukies R, Porst J-P, Kuhmann J, Berger M, Rath M. Results from the RIT-22 Technology Maturity Demonstration Activity. In: 50th AIAA/ASME/SAE/ASEE Joint Propulsion Conference. 2014. AIAA 2014-3421. https://doi.org/10.2514/6.2014-3421

10. Gnizdor R, Komarov A, Mitrofanova O, Saevets P, Semenenko D. High-impulse SPT-100D thruster with discharge power of 1.0...3.0 kW. In: 35th International Electric Propulsion Conference (IEPC), Atlanta, USA. 2017. IEPC-2017-40

11. Greenleaf AR. Photographic optics. New York: Macmillan; 1950. https://doi.org/10.1016/0016-0032(50)90339-5.

12. Ray SF. Applied photographic optics. Oxford: Focal Press; 2002. ISBN 9780240515403. https://doi.org/10.4324/9780080499253.

13. Jacobson RE, Ray SF, Attridge GG, Axford NR. The manual of photography: photographic and digital imaging. Oxford: Focal Press; 2000. ISBN 9780240515748. https://doi.org/10.4324/9780080510965.

14. Rowlands A. Physics of digital photography. London: IOP Publishing; 2020. ISBN 9780750312431. https://doi.org/10.1088/978-0-7503-1242-4.

15. Nasse H. Depth of Field and Bokeh. Technical report. Carl Zeiss AG; 2010 https://lenspire.zeiss.com/photo/en/article/overview-of-zeiss-camera-lenses-technical-articles

16. Altmann C, Leiter H, Kukies R. The RIT- $\mu$ X Miniaturized lon Engine System way to TRL 5 for an extended thrust range. In: 34th International Electric Propulsion Conference (IEPC), Hyogo-Kobe, Japan. 2015. IEPC-2015-274

\section{Submit your manuscript to a SpringerOpen ${ }^{\circ}$ journal and benefit from:}

- Convenient online submission

- Rigorous peer review

- Open access: articles freely available online

- High visibility within the field

- Retaining the copyright to your article

Submit your next manuscript at $\boldsymbol{s p r i n g e r o p e n . c o m ~}$ 